\title{
HACIA LA RECONQUISTA DEL RÍO: políticas, apropiaciones y usos en la ribera sur de la Región Metropolitana de Rosario (siglo XXI).
}

\author{
Cecilia Inés Galimberti \\ CONICET-CURDIUR, FAPYD, UNR \\ cecilia.galimberti@conicet.gov.ar
}

\section{RESUMEN}

Los waterfronts o frentes de agua se reposicionan en la actualidad como espacios de oportunidad, debates e intereses diversos en numerosas ciudades y áreas metropolitanas en todo el mundo. El presente trabajo toma como estudio la Región Metropolitana de Rosario (RMR) y se focaliza en interpretar las trasformaciones producidas entre las décadas 1990 y 2010 en su ribera sur. A través de la elaboración de cartografías de las localidades pertenecientes al corredor sur de la RMR se identifican los cambios en los usos del suelo registrados entre 1992 y 2017. Asimismo, se reflexiona críticamente sobre dichos cambios en relación con las políticas de planeamiento urbano-territorial, tanto desde la escala local como desde la mirada integrada de todo el frente fluvial. Se contribuye, de este modo, al debate de las transformaciones contemporáneas de los waterfronts latinoamericanos como también al rol del planeamiento metropolitano en torno a dichos procesos.

Palabras clave: frentes de agua - Región Metropolitana de Rosario - ordenamiento urbano-territorial planeamiento metropolitano

\begin{abstract}
The waterfronts are now repositioned as spaces of opportunity, debates and diverse interests in many cities and metropolitan areas around the world. The present work takes as case study the Metropolitan Region of Rosario (RMR) and focuses on interpreting the transformations produced between the 1990s and 2010 on its southern bank. Through the elaboration of cartographies of the towns belonging to the southern corridor of the RMR is comparatively analysed changes in the land uses produced between 1992 and 2017. Likewise, these changes are critically reflected in relation to urban planning policies. territorial, both from the local scale and from the integrated metropolitan view of the entire fluvial front. It contributes, in this way, to the debate of the contemporary transformations of Latin American waterfronts as well as to the role of metropolitan planning around these processes.
\end{abstract}

Key words: waterfronts - Metropolitan Region of Rosario - land-use plan - metropolitan planning 


\section{INTRODUCCIÓN}

Las ciudades ribereñas han tenido, históricamente, una dialéctica particular con el agua. Es este elemento el que, en muchos casos, es responsable de su identidad más profunda, la razón de ser de la misma. El río suele ser tanto el motor del crecimiento económico y productivo como también está vinculado estrechamente a la matriz cultural del territorio y sus habitantes. Sin embargo, desde las últimas décadas del siglo XX, frente a los cambios en los modos de producción y de las lógicas del sistema capitalista, entre otras causas, los frentes fluviales afrontan nuevas y diversas transformaciones que responden a intereses y demandas de diferentes actores intervinientes.

Por un lado, las instalaciones productivas (industriales/portuarias) construidas durante el período de industrialización, desde las últimas décadas del siglo XX tienden a resultar obsoletas (frente a los avances tecnológicos) y a presentar conflictos con otros usos urbanos (como la residencia) dado que suelen ocupar espacios centrales en las ciudades. Es así, que estos componentes tienden a ser desplazados hacia la periferia metropolitana y las antiguas instalaciones son refuncionalizadas y/o sustituidas para nuevas actividades. Por otro lado, también existe un redescubrimiento del paisaje fluvial, tanto desde la mirada turística-recreativa como del reconociendo de estos espacios como un valor estratégico para el mercado, la regeneración urbana y el marketing de las ciudades contemporáneas.

En este contexto, el presente trabajo se propone reflexionar críticamente sobre las transformaciones recientes de la ribera sur de la Región Metropolitana de Rosario (RMR), Argentina. Este territorio, especialmente en las últimas tres décadas, se encuentra sujeto a diversos cambios de usos del suelo que responden a exigencias de diversos intereses. Los avatares sociopolíticos-económicos que suceden tanto a nivel internacional como nacional, a partir de la década de 1980, ocasionan numerosas transformaciones para la región. La RMR se posiciona, en el período estudiado, como polo de exportación de gran relevancia internacional, resultando un nodo estratégico comunicacional y enclave logístico de gran importancia para Sudamérica. Los cambios que ocurren en el Gran Rosario son diversos y abarcan distintos frentes temáticos: producción, sociedad, territorio, economía, entre otros.

En esta investigación nos focalizamos en el frente fluvial del corredor sur de la RMR, el cual, a diferencia del corredor norte, dispone de gran cantidad de suelo rural, existiendo así una creciente demanda de transformación a suelo urbano. Por un lado, su posición geoestratégica sobre el río Paraná (especialmente en el marco de la Hidrovía Paraná -Paraguay) ocasiona que esta costa resulte ámbito elegido para la instalación de plantas industriales-portuarias. Por otro, el desarrollo de nuevos modos de habitar (mayormente en urbanizaciones cerradas, pero también abiertas) asociadas a la naturaleza, junto a la presión de promotores inmobiliarios, transforman gran parte de la costa metropolitana. Es así, que se sucede una acelerada transformación ribereña de ámbitos tradicionalmente rurales, sin una planificación integral previa. Por lo cual, se producen tensiones y conflictos a partir de la yuxtaposición de usos y dispersión de áreas urbanizadas en la amplia extensión rural de cada comuna y/o municipio.

Se propone, entonces, captar los elementos claves de la realidad estudiada, abordando las transformaciones urbano-territoriales de la ribera del Corredor Sur metropolitano y construyendo una serie de cartografías analíticas de los cambios de los usos del suelo que se producen en los últimos veinticinco años (1992-2017). Las principales fuentes utilizadas son: bases georreferenciadas del Servicio de Catastro e Información Territorial de la provincia de Santa Fe; cartografías del período 1990-2017 de las distintas municipales y comunas analizadas; imágenes satelitales históricas y actuales de dichas localidades disponibles en Google Earth; ordenanzas de usos del suelo, planes urbanos de los municipios estudiados y documentos de coordinación del Ente de Coordinación Metropolitana de Rosario (ECOM). La información fue confirmada por trabajo de campo llevado a cabo con la asistencia cualificada de actores locales, a través del cual se tomaron registros fotográficos y cartográficos de los cambios de usos del suelo.

El artículo se estructura en tres partes luego de la presente introducción. En la primera, se desarrolla brevemente la transformación de los frentes fluviales metropolitanos en las últimas décadas, sus características generales y nuevas dinámicas frente al contexto de la globalización y las demandas del mercado, el capital, el desarrollo tecnológico y el redescubrimiento recreativo del río. En la segunda parte, se presenta el caso de estudio, justificando su elección y relevancia. Para lo cual, en primer lugar, se explican los procesos de conformación y transformación del frente fluvial sur de la RMR y, posteriormente, se desarrollan los cambios que acontecen en esta ribera desde las últimas décadas del siglo XX. Frente a estas transformaciones, finalmente, se exponen las problemáticas y oportunidades del sector estudiado, haciendo énfasis en los avances e iniciativas de coordinación metropolitana emprendidos en la última 
década. La última parte, a modo de reflexiones finales, sintetiza los principales desafíos que atraviesa el ámbito estudiado, pero incorpora, a su vez, potencialidades y estrategias de planificación que den respuesta a los conflictos presentes. Estas reflexiones proponen contribuir tanto al conocimiento de los procesos existentes en los frentes fluviales latinoamericanos como a posibles desarrollos y articulaciones entre los instrumentos de planeamiento local y metropolitano.

\section{UNA NUEVA MIRADA SOBRE LOS FRENTES FLUVIALES}

Los procesos de transformación que acontecen en los frentes fluviales contemporáneos, si bien presentan conflictos, litigios y numerosos debates, también resultan una oportunidad de gran relevancia para las ciudades. La recualificación de riberas con grandes instalaciones obsoletas o sectores urbanos degradados no solo posibilita rediseñar fragmentos del tejido, sino también favorece al ordenamiento del conjunto de la ciudad, su funcionamiento y su imagen. La posibilidad de recuperar el paisaje del agua (cuando éste ha sido ocupado históricamente por componentes productivos, principalmente vinculadas a actividades portuarias) significa repensar el rol y la organización de toda el área urbana que rodea dicho waterfront. Por un lado, se permite imaginar la recuperación del acceso público como el desarrollo de nuevos lugares abiertos para la comunidad. Pero, por el otro lado, también resulta un estímulo expectante para la especulación del mercado inmobiliario (Bruttomesso, 1993, 2004).

Si bien en la historia puerto-ciudad existen intereses enfrentados, actualmente los mismos se multiplican en relación a las nuevas miradas sobre estos espacios. Administradores, políticos, ciudadanos, empresarios, entes portuarios, entidades económicas, entre otros, se convierten en actores con objetivos específicos (y generalmente contradictorios) sobre el destino de estas áreas. El redescubrimiento del valor del agua y de los frentes fluviales constituye un desafío para las ciudades costeras contemporáneas. Por lo cual, muchas ciudades toman el desafío de reconquistar sus waterfronts. Se redescubre así las posibilidades que brinda esta condición y se propone reinstaurar las complejas relaciones entre tejido urbano y agua (en muchos casos negadas durante décadas). La recuperación y reconversión del frente costero se convierte en tema estratégico de las agendas de planeamiento local-regional.

Especialmente en las últimas décadas, las transformaciones y nuevos desarrollos en los frentes fluviales han sido una parte esencial de la vida de gran parte de las urbanizaciones costeras. Si bien la transformación de waterfronts resulta un proceso en curso en diversos rincones del mundo, ya se han realizado diversas intervenciones que nos permiten, a través de su análisis crítico, reflexionar sobre estos espacios. No obstante, estas acciones no siempre son exitosas. La experiencia nos ha demostrado, en muchos casos, que las intervenciones propuestas se enfocan a responder a determinados intereses económicos, a repetir modelos genéricos ya realizados en otros países (generalmente muy distintos), a museificar espacios urbanos, o a transformar estas áreas en estructuras parecidas a un parque de diversiones (Galimberti, 2014).

En Europa, dos casos significativos de reconversión de frentes de agua han sido los Docklands en Londres y la transformación de la ribera de Rotterdam. En el primero, la reconversión de áreas portuarias e industriales del río Támesis, en un lugar estratégico de Londres, ha conducido a uno de los desarrollos de waterfronts más paradigmáticos a nivel global. Este proceso, iniciado en la década de 1980, si bien constituye un programa complejo, está liderado por el desarrollo empresarial corporativo (a través del consorcio London Docklands Development Corporation) con una fuerte presencia de la inversión privada (especialmente en el sector central del proyecto). Si bien este gran proyecto urbano logra reposicionar el área dentro de la ciudad, generando nuevas e importantes centralidades (como también en Inglaterra y en todo el mundo dado la cantidad de empresas internacionales que instalan aquí sus oficinas), también acarrea diversos procesos de desigualdad y gentrificación para los pobladores originales del área.

Por otra parte, el caso de Rotterdam resulta representativo de la transformación metropolitana de los frentes de agua. Se trasladan las infraestructuras portuarias e industriales a la periferia de la ciudad (hacia la desembocadura del río Mosa) y se crean nuevas áreas provistas de servicios, equipamientos y desarrollos tecnológicos, de manera que se posiciona en los últimos años como el principal puerto de Europa. A su vez, la desafectación de usos portuarios en el centro de Rotterdam posibilita llevar a cabo un proceso de refuncionalización de su ribera, a través de proyectos y programas diversos que incorporan sectores residenciales, recreativos, culturales y comerciales. Es así, que se posibilita restituir el diálogo entre la ciudad, el puerto y el río, desde una perspectiva integrada entre distintos usos en todo el frente fluvial metropolitano. 

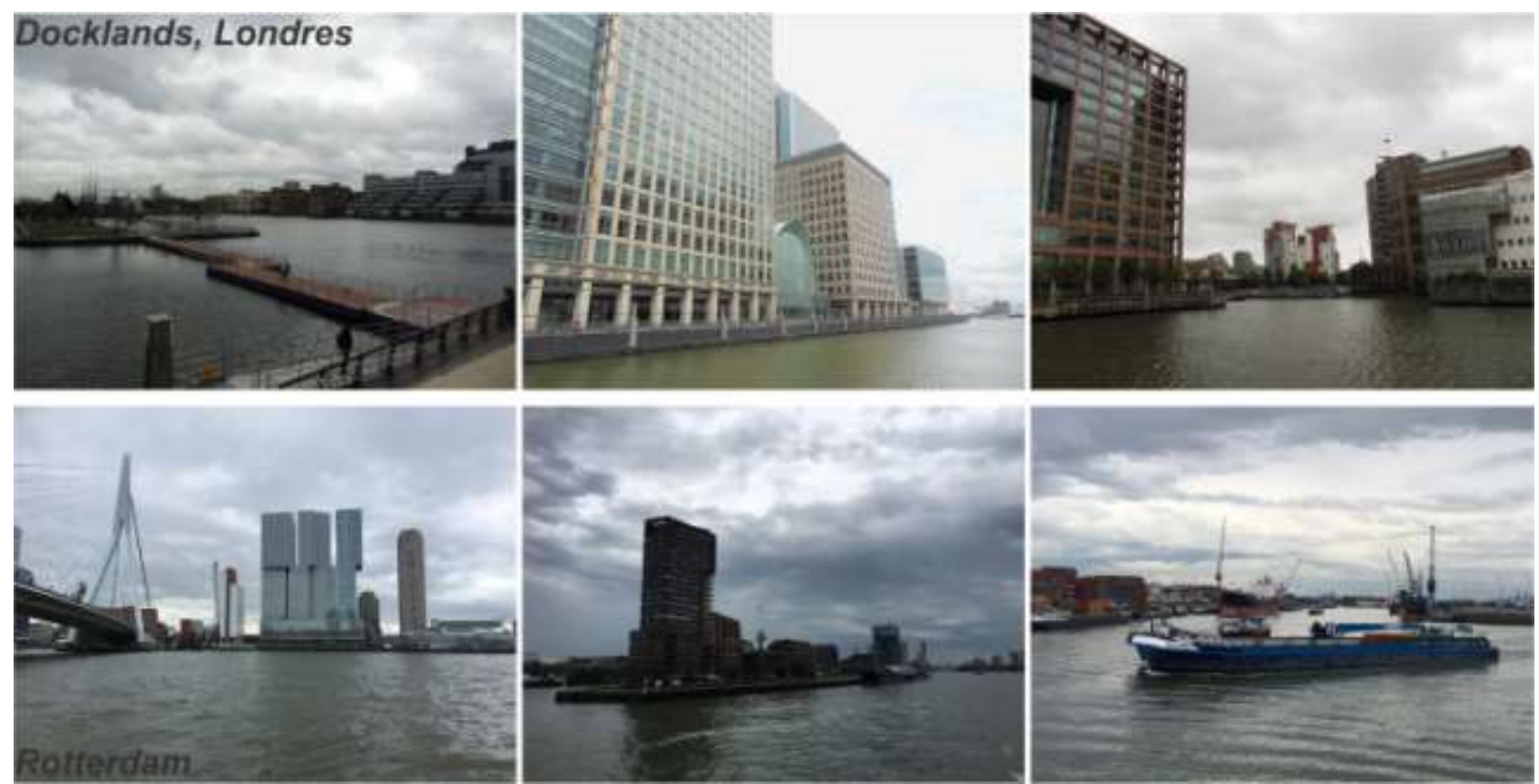

Figura 1. Transformaciones de waterfronts en Europa. Arriba: Docklands en Londres. Abajo: Frente fluvial en Rotterdam.

Fotos de la autora.

En América Latina también se realizan diversas reconversiones de frentes de agua, especialmente desde las últimas décadas del siglo XX. No obstante, en términos generales, el contexto sociopolítico-económico de los países latinoamericanos ocasiona que estas grandes reconversiones presenten características particulares. Por ejemplo, la acción de las demandas privadas del capital (muchas veces con gran número de inversores extranjeros) tienden a privatizar los espacios a refuncionalizar y a profundizar las desigualdades existentes en la ciudad. También así, las reestructuraciones portuarias latinoamericanas presentan una gran influencia de modelos ya realizados en Europa o Norteamérica, tendiendo a imitar casos que distan en gran medida de la realidad local. La búsqueda del marketing urbano, la atracción de empresas extranjeras y/o la realización de nuevos megaproyectos inmobiliarios privados tienen a superar la recuperación de estos espacios para toda la sociedad local, a través de un nuevo diálogo entre el tejido urbano y el agua.
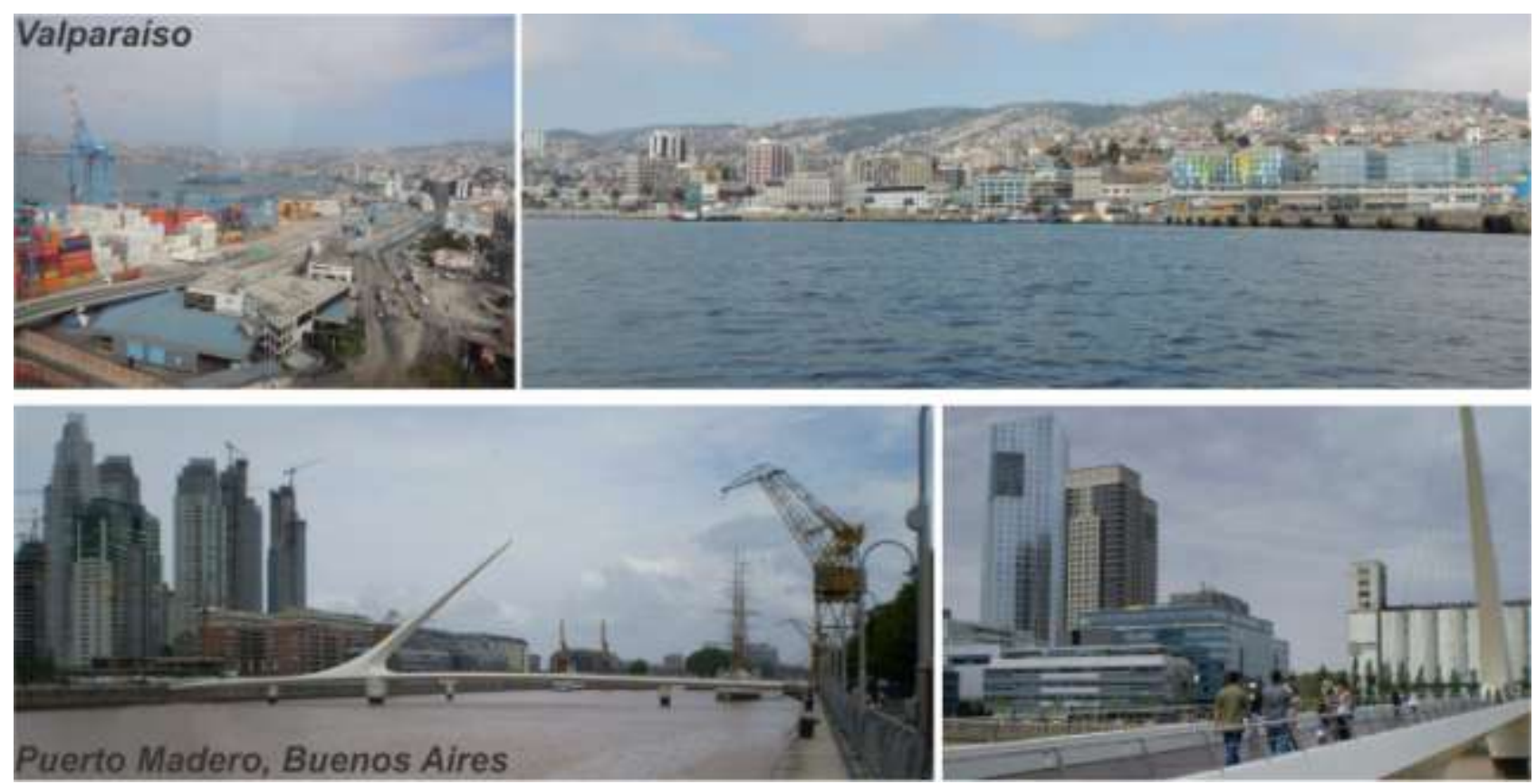

Figura 2. Transformaciones de waterfronts en Latinoamérica. Arriba: Frente fluvial en Valparaíso. Abajo: Puerto Madero en Buenos Aires.

Fotos de la autora. 
La refuncionalización de estos frentes de agua resulta materia de interés para múltiples actores: municipios y comunas, sociedad en general, desarrolladores inmobiliarios, entre otros. No obstante, los intereses que motivan a los mismos a reclamar la revitalización de estas riberas resultan contradictorios entre sí. Por ejemplo, mientras que algunos solicitan su recuperación para la creación de espacios públicos, la rehabilitación ambiental ribereña y la reconexión con la trama urbana existente, otros plantean privatizarla, mayormente en oficinas y residencias para sectores altos y/o medios-altos de la población. A su vez, desde las autoridades municipales, muchas veces se encaran estas reconversiones a fin de lograr una mayor atracción turística, pero también para atraer posibles inversiones privadas. Por lo cual, la dificultad esencial que involucra a estas reconversiones es la reconciliación de los diversos objetivos, intereses e influencias involucrados.

Las transformaciones de waterfronts, si bien presentan procesos universales, también poseen características específicas al propio contexto donde se desarrollan. Ambas dimensiones, lo local y lo global, se encuentran presentes en estas reconversiones fluviales. Si bien su articulación no resulta tarea fácil, al analizar la relación ciudad-puerto y su transformación en general podemos reconocer un conjunto común de factores subyacentes a los casos exitosos. Como plantea Brian Hoyle (2000:415), el posible éxito de estas transformaciones depende esencialmente de tres cosas: "integración, integración, integración. Primero, integración del pasado y el presente; segundo, integración de los objetivos e intereses contrastantes; y tercero, integración entre las comunidades y localidades involucradas". Por lo cual, la articulación entre lo local y lo global resulta, entonces, componente clave en los desarrollos de transformaciones ribereñas contemporáneas (Galimberti, 2015). El estudio de estos casos nos permite reflexionar así, sobre los procesos presentes en la Región Metropolitana de Rosario en las últimas décadas.

\section{REGIÓN METROPOLITANA DE ROSARIO (RMR)}

La RMR se localiza a la vera del río Paraná, al sur de la provincia de Santa Fe. La misma se constituye como una de las principales regiones metropolitanas de Argentina (actualmente registra más de 1.400 .000 habitantes), luego de Buenos Aires (RMBA) y Córdoba (RMC). Se localiza prácticamente equidistante de ambas a $300 \mathrm{~km}$ al noroeste de la RMBA y a $400 \mathrm{~km}$ al sureste de la RMC. Si bien la ciudad de Rosario y su territorio aledaño adquiere gran relevancia a partir de la segunda mitad del siglo XIX, desde las últimas décadas del siglo XX se reposiciona estratégicamente tanto a nivel nacional como internacional.

Su localización geográfica clave, en el marco de la hidrovía Paraná-Paraguay y del corredor biocéanico Chile-Uruguay (posibilitado tras la inauguración del puente Rosario-Victoria en el 2003), junto a las condiciones topográficas de puerto natural en sus barrancas y el importante calado del río, han atraído en las últimas décadas numerosas plantas productivas y puertos exportadores, entre otros desarrollos, que se asientan en esta región. En el marco de la sojización y el boom de la exportación de commodities, la planicie ondulada de la RMR resulta de gran riqueza, tanto para la producción primaria como para su procesamiento y exportación.

En la actualidad, no solo es el mayor polo exportador de soja y subproductos en la Argentina, con el $85 \%$ del total nacional, sino que, en el año 2016, también se posiciona como el nodo exportador sojero más importante del mundo. Dado que con 39,36 millones de toneladas de poroto de soja, harinas y aceite, supera al distrito aduanero de Nueva Orleans en EE.UU y al nodo portuario de Santos, Brasil, hasta entonces principales exportadores a escala global (Calzada y Di Yenno, 2017). Es así, que el crecimiento y potencial que presenta la RMR ocasiona diversas y aceleradas transformaciones.

Según sus características, y a los fines de posibilitar su análisis, la RMR se divide en cuatro áreas: 1. La ciudad cabecera, Rosario (que presenta una histórica macrocefalia en la región); 2. El corredor norte, que comprende a las localidades ubicadas al norte de la ciudad cabecera y mayoritariamente se localizan a la vera del Paraná; 3 . El cuadrante oeste, el cual abarca un amplio arco territorial que se localiza al oeste de Rosario, y 4. El corredor sur, que comprende a las ciudades y comunas que tienen sus jurisdicciones al sur de Rosario y son linderas al río Paraná.

En el presente trabajo, nos focalizamos en el análisis crítico del corredor sur de la RMR. 

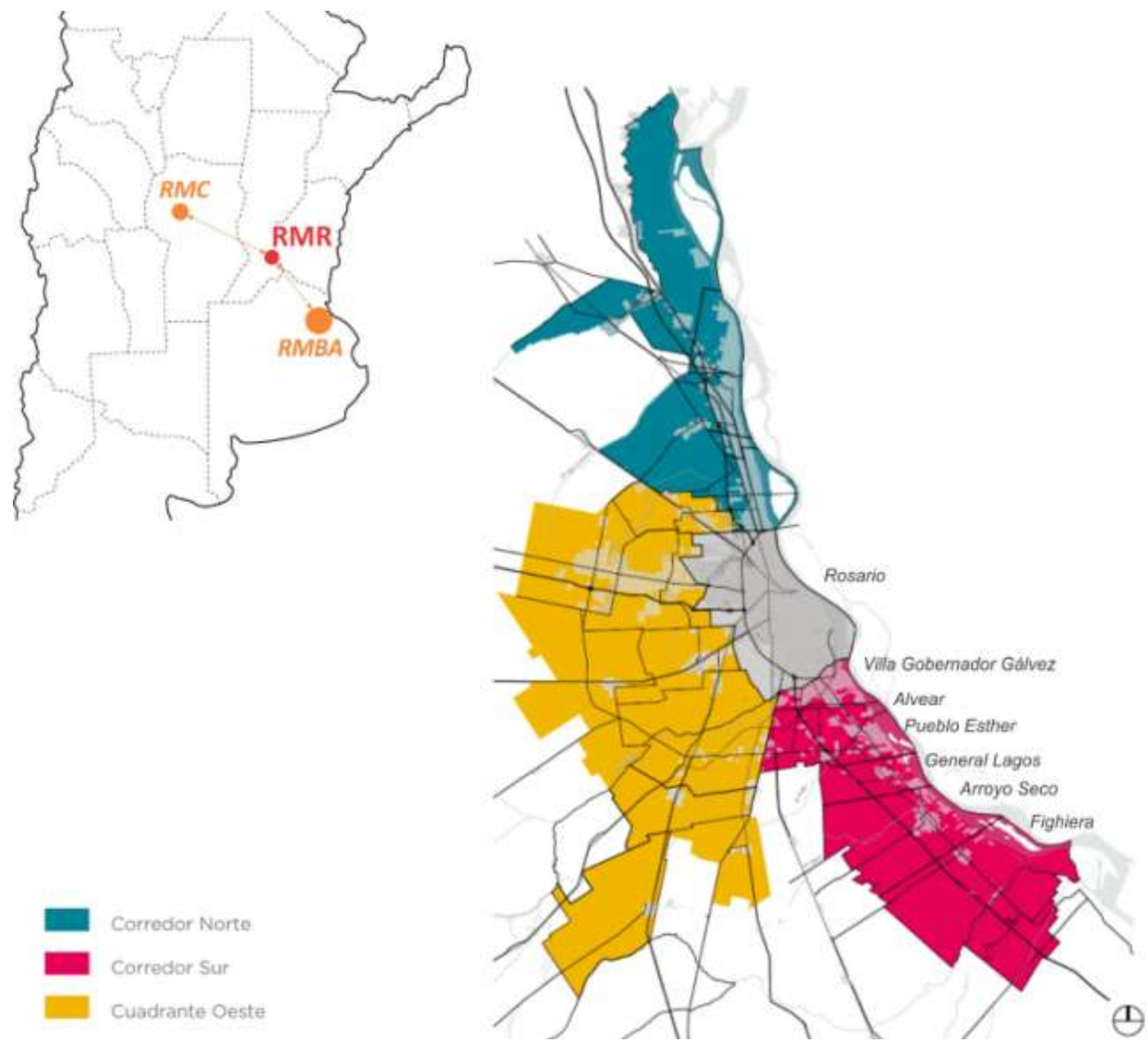

Figura 3. Localización de la Región Metropolitana de Rosario (RMR) y su caracterización en corredores. Elaboración propia en base a (Fein, 2017).

\subsection{Caracterización del corredor sur de la Región Metropolitana de Rosario.}

El corredor sur de la RMR comprende a las comunas y municipios localizados a la vera del Paraná, al sur de Rosario: Villa Gobernador Gálvez, Alvear, Pueblo Esther, General Lagos, Arroyo Seco y Fighiera'. Este sector de estudio presenta una sucesión de arroyos, paleocañadas y cañadas que atraviesan transversalmente el territorio, confluyendo al Paraná. Asimismo, la topografía de su frente fluvial presenta condiciones de barranca alta (propicias para actividades portuarias), pero también prosee bajíos, playas naturales y humedales con vegetación de gran relevancia.

Al igual que el resto de la RMR, este sector geográfico se transforma aceleradamente a partir de la segunda mitad del siglo XIX, especialmente con la infraestructuración ferroviaria. Si bien existían poblaciones dispersas, es a partir del desarrollo del ferrocarril que se conforman la mayoría de las localidades. Es así, que el Ferrocarril General Bartolomé Mitre resulta estructurador de este corredor, creciendo los diferentes

\footnotetext{
${ }^{1}$ Se consideran estas localidades para el presente trabajo, pero, actualmente está en curso la inclusión de las localidades de Pavón, Empalme Villa Constitución y Villa Constitución como miembros del Ente de Coordinación Metropolitana de Rosario (ECOM) y que, por su ubicación geográfica, formarán parte del corredor sur.
} 
poblados en torno a sus estaciones ferroviarias. Es por esto por lo que la mayoría de los centros urbanos históricos se encuentran alejados del río a $3 \mathrm{Km}$ aproximadamente ${ }^{2}$.

Posteriormente, con el desarrollo del sistema vial se realiza en 1936 la pavimentación de la ruta nacional $\mathrm{N}^{\circ} 9$ que conecta Rosario y Buenos Aires (actual ruta provincial $\mathrm{N}^{\circ} 21$ en el sector estudiado), la cual discurre paralela a la traza del ferrocarril, entre Empalme Villa Constitución y Arroyo Seco, y luego se distancia un kilómetro hasta el ingreso a Rosario. Luego de la realización de dicha ruta se incrementan las áreas urbanizadas a ambos márgenes de ésta, como también se tiende a urbanizar los sectores intermedios hasta las vías ferroviarias.

También así, desde la primera posguerra comienza a crecer la industria nacional y la instalación de nuevas plantas productivas. Por ejemplo, en 1924, la instalación del Frigorífico Swift en la actual Villa Gobernador Gálvez acarrea numerosos cambios y transformaciones en los usos del suelo. Además de atraer posteriormente la instalación de otras industrias, también atrae a inmigraciones de trabajadores que se instalan próximas a la misma y se crea la urbanización denominada como Pueblo Nuevo. La crisis internacional de 1929-1932 junto a otros factores político-económicos nacionales inciden en la consolidación de la Industria Sustitutiva de Importaciones (ISI) en la Argentina. Si bien el corredor norte es el sector de la RMR que mayores radicaciones industriales presenta en dicho período, también así en el sector sur se instalan plantas productivas de gran relevancia, como Cilsa y Acindar en Villa Constitución en 1947. En la década de 1960 se instalan Basf en General lagos y Shell en Arroyo Seco.

Entre fines de la década de 1960 y comienzos de los '70 se proyecta la autopista Rosario-Buenos Aires, paralela a la ex ruta nacional $\mathrm{N}^{\circ} 9$, a unos $3 \mathrm{~km}$ promedio distanciada de la ruta al suroeste. El primer tramo se construye hasta San Nicolás (provincia de Buenos Aires), concretándose su totalidad en 1987. La realización de esta vía rápida de comunicación acarrea numerosos cambios en los usos del suelo, no solo en sus márgenes, sino también en el territorio comprendido entre la autopista y la ruta, en especial en torno a los caminos de ingreso de cada poblado.

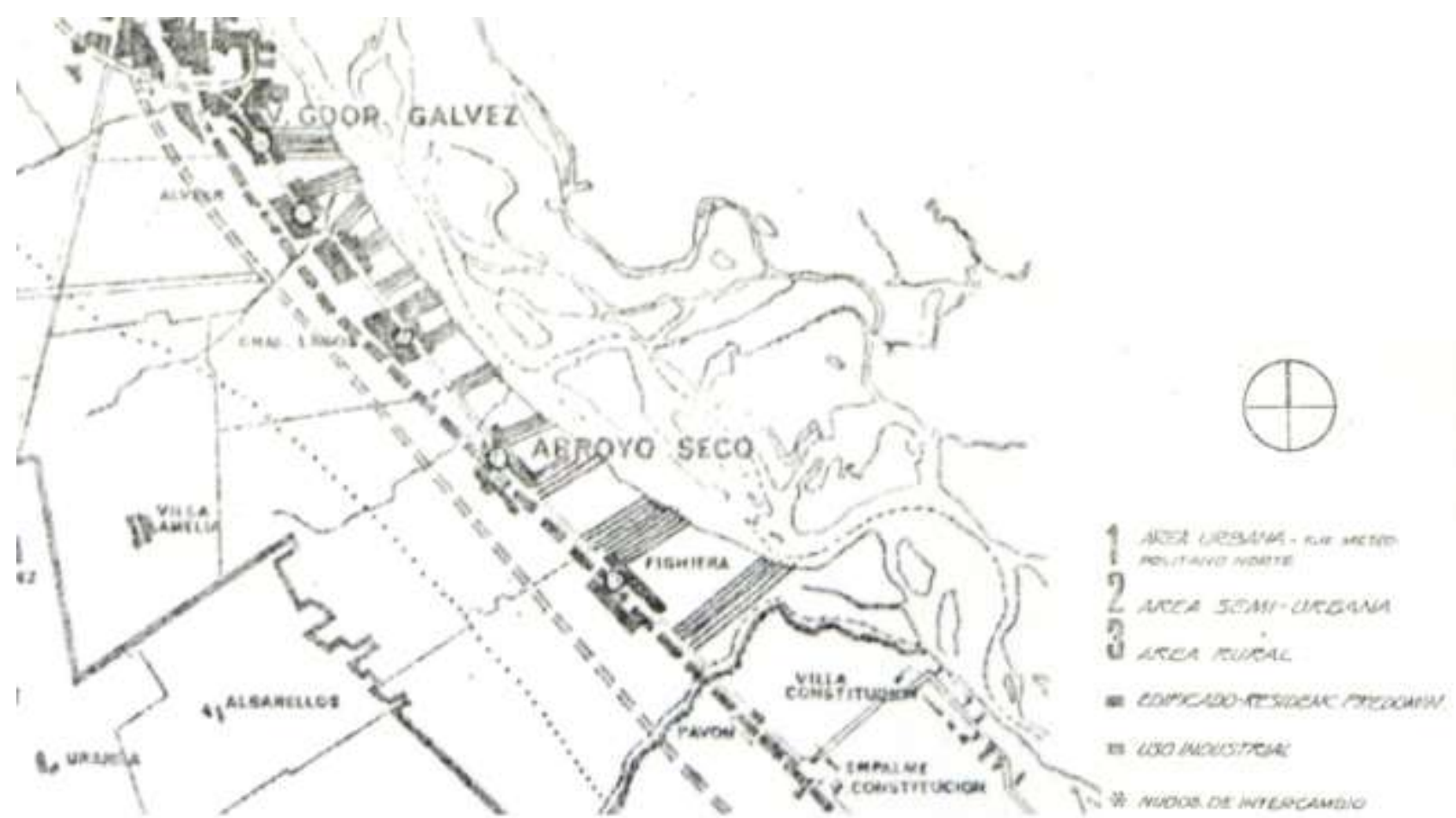

Figura 4. Análisis del corredor sur del Área Metropolitana de Rosario según Organismo de Prefectura del Gran Rosario 1972. (Ansaldi et. al, 1972)

Asimismo, entre las décadas de 1960-1970 se incrementa la expansión urbana de diversas localidades de la región. Distintas comunas y municipios aprueban loteos correspondientes a nuevas urbanizaciones,

\footnotetext{
${ }^{2}$ A excepción de Pueblo Esther que, si bien no surge en torno a una estación, se desarrolla a orillas del Paraná y crece a partir de la habilitación de la estación General Lagos, como un pequeño poblado subsidiario conocido como "Colonia Esther" al poblado que se crea en torno a la mencionada estación y denominado como ésta (General lagos). Recién es en 1975 que se separan las comunas de Pueblo Esther y General Lagos como dos localidades autónomas.
} 
muchas de ellas próximas a caminos viales y alejadas de las plantas urbanas históricas. También así, en el corredor sur, se aprueban nuevos loteos junto al río Paraná. Si bien muchos de éstos no se efectivizan ni son ocupados en ese momento, constituyen el germen de la dispersión territorial presente en gran parte del ámbito metropolitano de Rosario. Es importante destacar que, si bien este sector acarrea importantes incrementos de su superficie urbanizada, no llega a producirse una conurbación del corredor, a diferencia de como sí sucede en el corredor norte. De este modo, resulta representativo que la mayoría de los núcleos urbanos se encuentran separados entre sí por suelo rural, identificándose claramente la planta de cada municipio y comuna.

\subsection{Transformaciones del corredor sur de la RMR entre 1992-2017.}

En el contexto de la crisis económica de Argentina y la fuerte adhesión a políticas neoliberales, la apertura de las importaciones, la convertibilidad y la privatización del Estado, entre otras acciones, desde fines de los ' 80 y comienzos de los ' 90 , la RMR se sumerge en un nuevo período de transformación socio-territorial. El corredor sur también refleja estos cambios, entre los que se destacan la instalación de nuevos componentes industriales y el desarrollo de urbanizaciones, muchas de ellas cerradas y alejadas de las plantas urbanas. Asimismo, sucede un redescubrimiento del paisaje bucólico del río que ocasiona que varias de las nuevas urbanizaciones se localicen en el frente fluvial (con caletas y amarras que modifican la barranca). Se produce así un fuerte incremento de suelo urbano (ya sea para actividades recreativas, residenciales o industriales).

Si bien, como ya mencionamos, el corredor norte es el principal territorio elegido para la instalación de plantas productivas portuarias y/o industriales, esta tendencia, en menor medida, también sucede en el corredor sur. La instalación de General Motors en 1997, en la intersección de la autopista Rosario-Buenos Aires y la ruta nacional AO12, renueva el auge de la industria automotriz y genera la localización de otras empresas y componentes productivos en la zona. A fin de impulsar esta tendencia, en 1995 la legislatura provincial sanciona la ley $N^{\circ} 11.285$ que promociona la radicación de industrias metalmecánicas a los márgenes de la autopista a Buenos Aires en las jurisdicciones de Alvear, Pueblo Esther, General Lagos y Villa Amelia. Por otra parte, se consolida el Parque Industrial Alvear y se instalan nuevas plantas productivas sobre la ribera sur del Paraná, como, por ejemplo: Cargill S.A.C.I, Ultrapetrol, Louis Dreyfus, Toepfer, entre otras.

\begin{tabular}{|l|c|c|}
\hline CRECIMMIENTO POBLACIONAL & $\begin{array}{c}\text { Variación intercensal } \\
1991-2001\end{array}$ & $\begin{array}{c}\text { Variación intercensal } \\
2001-2010\end{array}$ \\
\hline ROSARIO & $0,05 \%$ & $4,42 \%$ \\
\hline VILLA GOBERNADOR GÁLVEZ & $18,36 \%$ & $8,19 \%$ \\
\hline ALVEAR & $5,62 \%$ & $134,5 \%$ \\
\hline PUEBLO ESTHER & $97,7 \%$ & $57,89 \%$ \\
\hline GENERAL LAGOS & $51,30 \%$ & $57,19 \%$ \\
\hline ARROYO SECO & $13,68 \%$ & $13,98 \%$ \\
\hline FIGHIERA & $7,25 \%$ & $27,23 \%$ \\
\hline
\end{tabular}

Tabla 1. Variación intercensal en Rosario y en las localidades pertenecientes al Corredor Sur en los últimos tres censos nacionales (1991, 2001 y 2010).

Elaboración propia en base a INDEC.

Asimismo, se registra una gran movilidad de la población en las últimas décadas. Como vemos en la Tabla 1, la ciudad de Rosario desacelera su crecimiento poblacional, con relación a los períodos anteriores, mientras que aumenta la cantidad de habitantes en otros centros urbanos (por ejemplo, Alvear y Pueblo Esther incrementan su población entre el 95 y 135\% en diez años). Esto sucede por diversos motivos: por un lado, debido a las industrias que se instalan en las últimas décadas en localidades de la RMR y sus trabajadores deciden vivir próximos a éstas. Por otra parte, el alto valor del suelo urbano y el acceso a la vivienda propia en Rosario ocasiona que muchas familias jóvenes accedan a la posibilidad de construir su 
vivienda accediendo a lotes con menos servicios e infraestructuras y, por ende, a mucho menor precio. Es así, que la tendencia que ya se prefiguraba en décadas anteriores de localidades como Pueblo Esther de posicionarse como poblado para casas quinta finisemanales y/o vacacionales, también se consolida ahora para residencia permanente.

Además, el boom internacional del modelo de vivienda suburbano, vinculado a un mayor contacto con la naturaleza y a la posibilidad de acceder a la tipología de casa unifamiliar con jardín propio, junto a la presión de los desarrolladores para habilitar suelo rural en urbano (y obtener cuantiosas plusvalías), ocasionan que esta tendencia siga en auge. A su vez, los grupos de alto poder adquisitivo buscan estos nuevos modos de vida en barrios cerrados, en pos de mayor seguridad, privacidad y acceso a amenities junto a sus residencias (como club house, canchas de deportes o amarras náuticas privadas). El Paraná resulta una pieza clave que atrae a numerosos emprendimientos privados de este tipo en su ribera. La contracara del aumento de numerosos barrios privados es el surgimiento de nuevos asentamientos irregulares y el crecimiento de villas de emergencia ya existentes. Asimismo, se denota el incremento del déficit de vivienda en la región, como la cantidad de familias que habitan en hogares que no cumplen con condiciones mínimas de salubridad. De este modo, la desigualdad y el contraste entre la riqueza y la pobreza se profundiza y se hace notorio en el ámbito estudiado.

A fin de hacer foco en dichas transformaciones, analizamos los cambios de usos del suelo en los últimos veinticinco años en cada una de las localidades que conforman el corredor.

\section{- Villa Gobernador Gálvez:}

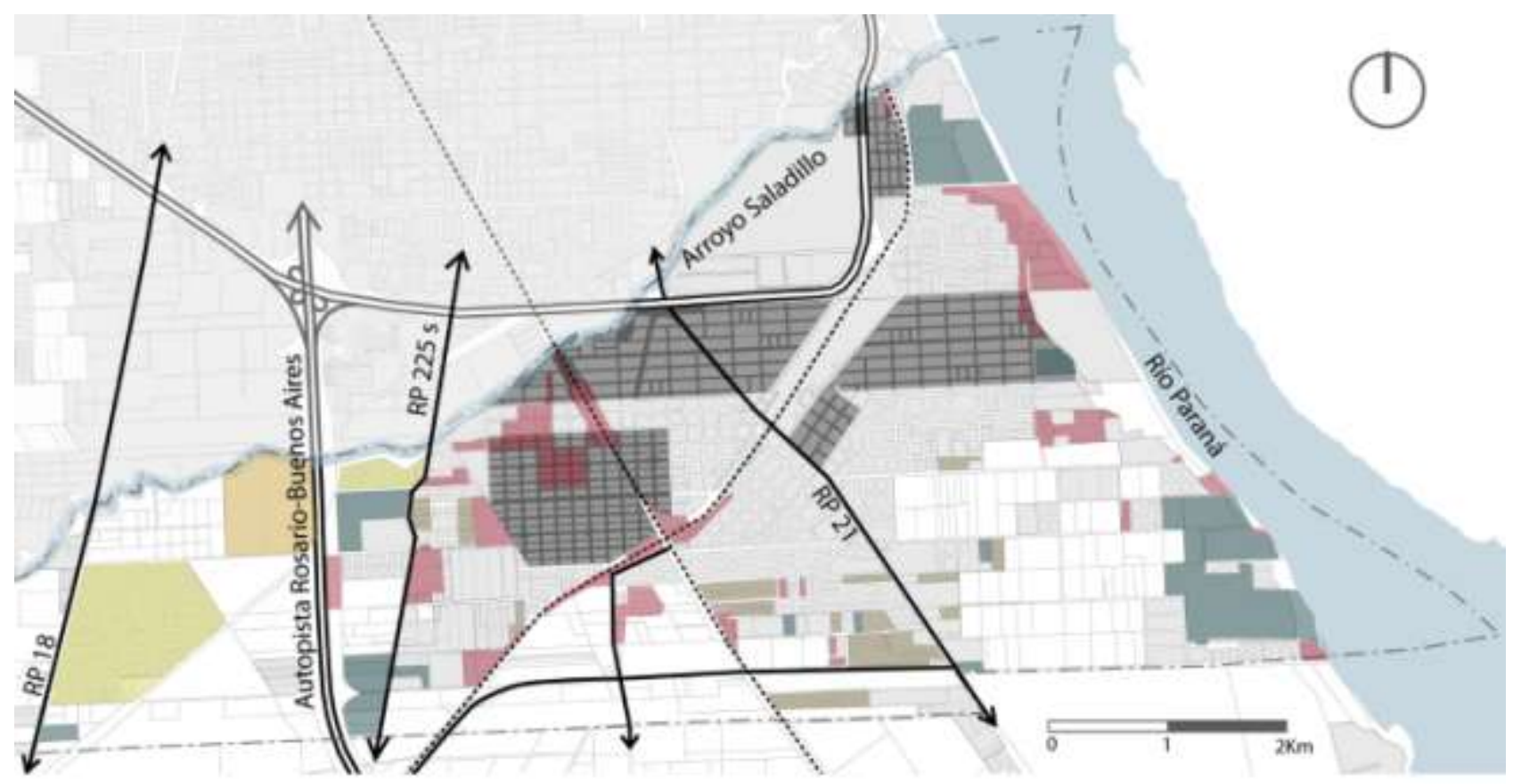

Referencias:

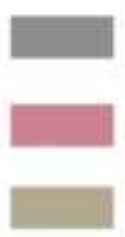

Planta urbana original (Situación en 1930)

Asentamientos irregulares

Nuevas urbanizaciones realizadas entre 1992-2017
Nuevas instalaciones industriales realizadas entre 1992-2017

Urbanizaciones aprobadas antes de $1992 \mathrm{sin}$ ocupar y a desafectar como suelo urbano Centro GIRSU (realizado entre 2015-2018)

Figura 5. Transformaciones en el uso del suelo de Villa Gobernador Gálvez entre 1992 y 2017. Elaboración propia.

Villa Gobernador Gálvez (VGG) es el segundo municipio más poblado de la región (luego de Rosario). Entre los procesos más significativos que suceden en su jurisdicción se destaca el notable crecimiento de los asentamientos irregulares presentes en la localidad. Especialmente esta tendencia se profundiza en la última década. Se registran más de una veintena de estos asentamientos. Asimismo, también se aprueban 
nuevas urbanizaciones, generalmente localizadas en la periferia de la planta urbana existente. No obstante, también se denota el completamiento de la planta ya urbanizada, aunque en la actualidad aún persiste gran cantidad de tierra urbana vacante.

Asimismo, el rol industrial también crece considerablemente en el período estudiado, ocupando dicho uso una gran proporción de la jurisdicción, aunque localizada de manera dispersa y desordenada. Mayormente se concentran las instalaciones industriales sobre el frente ribereño del Paraná (frigoríficos Swift y Paladini, Unilever y Cargill), pero también sobre la ruta provincial $\mathrm{N}^{\circ} 21$ y entre la autopista Rosario-Buenos Aires y la ruta provincial $\mathrm{N}^{\circ} 225-\mathrm{s}$. De este modo, a pesar de su extenso frente fluvial y sectores de barranca baja que posibilitan un contacto directo con el río, la presencia de grandes componentes productivos yuxtapuestos con asentamientos irregulares impide la existencia de espacios públicos ribereños o de enclaves recreativos a los que puedan acceder la población.

Por otra parte, VGG también presenta su límite jurisdiccional norte con Rosario sobre el margen del arroyo Saladillo. Sin embargo, a pesar de presentar un gran potencial frente a los recursos hídricos-ambientales de gran relevancia, este sector también se encuentra ocupado por establecimientos industriales y asentamientos irregulares. A su vez, se registra una alta vulnerabilidad del agua del arroyo debido a la presencia de basurales a cielo abierto en sus márgenes. Sin embargo, el reciente desarrollo de un Centro de Gestión Integral de Residuos Sólidos Urbanos (GIRSU) localizado en la intersección del Saladillo y la autopista, ya ha posibilitado el saneamiento integral de gran parte del Saladillo.

\section{- Alvear:}

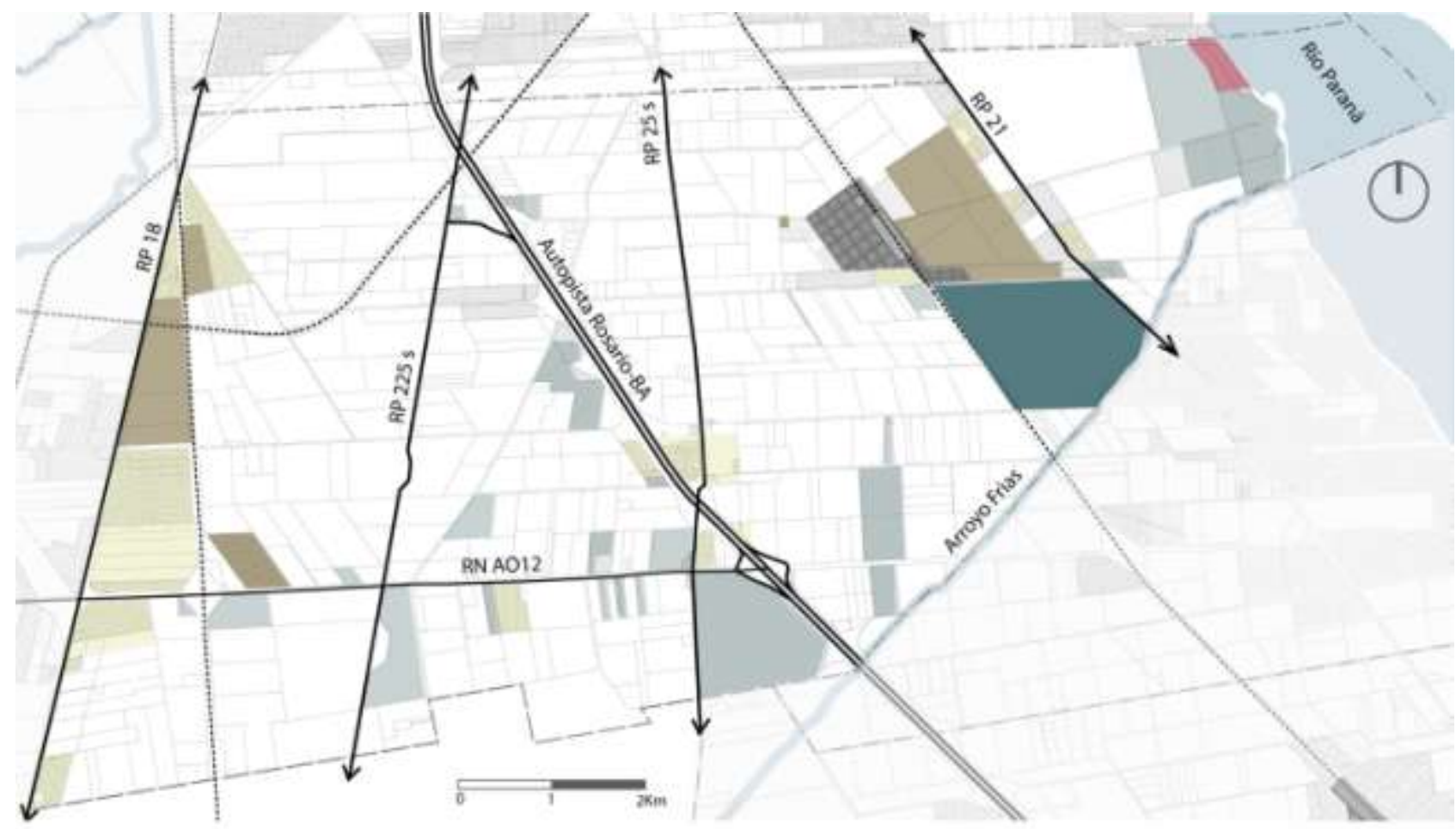

Referencias:

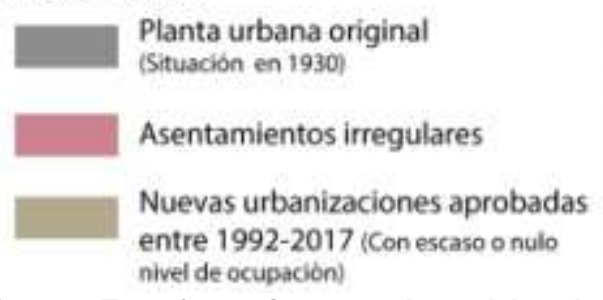

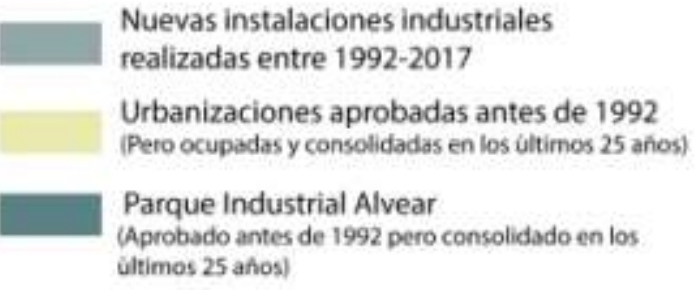

Nuevas instalaciones industriales

Urbanizaciones aprobadas antes de 1992

Parque Industrial Alvear ultimos 25 ahos)

Figura 6. Transformaciones en el uso del suelo de Alvear entre 1992 y 2017.

Elaboración propia.

La Comuna de Alvear en las últimas décadas consolida su vocación como polo productivo regional de importancia, incrementado la superficie destinada a suelo rural en industrial. Si bien se produce una notable 
concentración de industrias en relación con la ruta nacional AO12, la autopista Rosario-Buenos Aires y la ruta provincial $\mathrm{N}^{\circ} 21$, también se localizan de manera dispersa en la jurisdicción, en áreas calificadas tradicionalmente como suelo rural. A su vez, su escaso frente fluvial sobre el Paraná se encuentra prácticamente ocupado por usos productivos: Cargill Punta Alvear y Ultrapetrol, a excepción de un pequeño enclave al norte de la jurisdicción que existe un asentamiento irregular de pescadores en la barranca baja. Asimismo, al sureste linda con el arroyo Frías, el cual también se encuentra mayormente ocupado o próximo a usos industriales en Alvear, mientras que su margen sur (perteneciente a la localidad de Pueblo Esther), presenta usos rurales, recreativos y residenciales.

La dispersión no sólo es característica de los desarrollos industriales, sino también de las áreas urbanizadas para residencia. En los últimos veinte años, además de ocuparse y consolidarse numerosos loteos aprobados durante la década de 1970 y separados aproximadamente $10 \mathrm{~km}$ del caso histórico, también así se aprueban nuevas urbanizaciones, de manera que se tiende a triplicar la planta urbana original. La alta dispersión urbana presente en Alvear genera numerosos inconvenientes; tanto en relación con la provisión de servicios, infraestructuras y equipamientos (de salud, educación, recreativos, entre otros), registrando un alto nivel de déficit en los loteos alejados del centro, como también se registran problemas resultantes por la yuxtaposición de usos sin una planificación adecuada (por ejemplo, la fumigación aérea con agroquímicos en las áreas rurales lindantes a las residenciales o la presencia de industrias contaminantes en sectores con viviendas).

\section{- Pueblo Esther:}

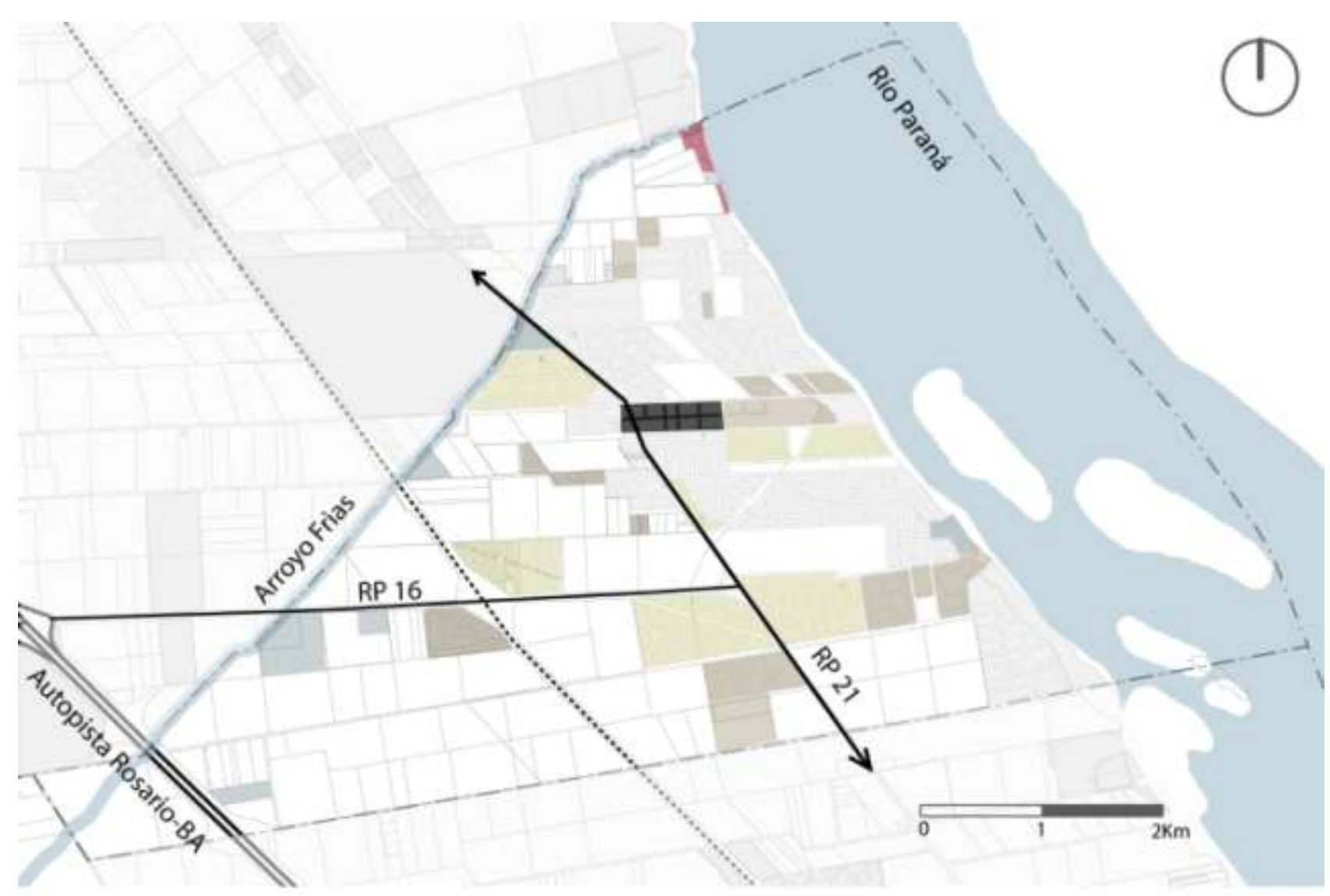

\section{Referencias:}

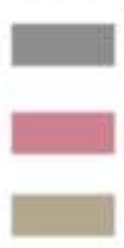

Planta urbana original situación en 1930;

Asentamientos irregulares

Nuevas urbanizaciones aprobadas entre

1992-2017 (Con escaso o nulo nivel de ocupación)
Nuevas instalaciones industriales realizadas entre 1992-2017

Urbanizaciones aprobadas antes de 1992 (Pero ocupadas y consolidadas en los ultimos 25 antos?

Figura 7. Transformaciones en el uso del suelo de Pueblo Esther entre 1992 y 2017.

Elaboración propia. 
La comuna de Pueblo Esther, a diferencia de las localidades anteriores, posee un rol predominante recreativo-residencial. Si bien se localizan componentes productivos industriales sobre la ruta provincial $N^{\circ} 16$ (continuación de la AO12), la ruta provincial №21 y el frente ribereño (mayormente areneras), estas actividades representan un porcentaje considerablemente menor en relación con la residencia. Esta comuna consolida su vocación para casas finisemanales como para residencia permanente, aprobándose en las últimas décadas nuevos loteos y urbanizaciones cerradas. Sobre el frente ribereño se destaca el desarrollo del barrio privado "Country La Bahía" de 12 hectáreas y con caleta propia para embarcaciones privadas. Cercano a éste, se encuentra el barrio cerrado "Campos de Esther" de 16 hectáreas. En relación con las rutas provinciales $\mathrm{N}^{\circ} 16$ y 21 se encuentran las urbanizaciones privadas Sol Paraná y Country Gimnasia y Esgrima respectivamente.

Asimismo, se consolida la ocupación en los loteos aprobados en los períodos anteriores, incrementando la superficie efectivamente ocupada y edificada en la localidad. No obstante, la falta de planificación integral del desarrollo de estas nuevas urbanizaciones, han ocasionado que exista una desconexión territorial debido a que el poblado se conforma como una suma de fragmentos individuales. Se denota, entonces, que la comuna se compone de dos partes: un sector vinculado al río y otro sector con relación a las rutas provinciales. Existen grandes superficies rurales (con la aplicación de agroquímicos tóxicos para la población cercana a los campos) o ya urbanizadas, pero no ocupadas entre los distintos sectores urbanos. A su vez, también se identifican sobre el frente ribereño asentamientos irregulares (aproximadamente 70 familias), mayormente de pescadores.

\section{- General Lagos:}

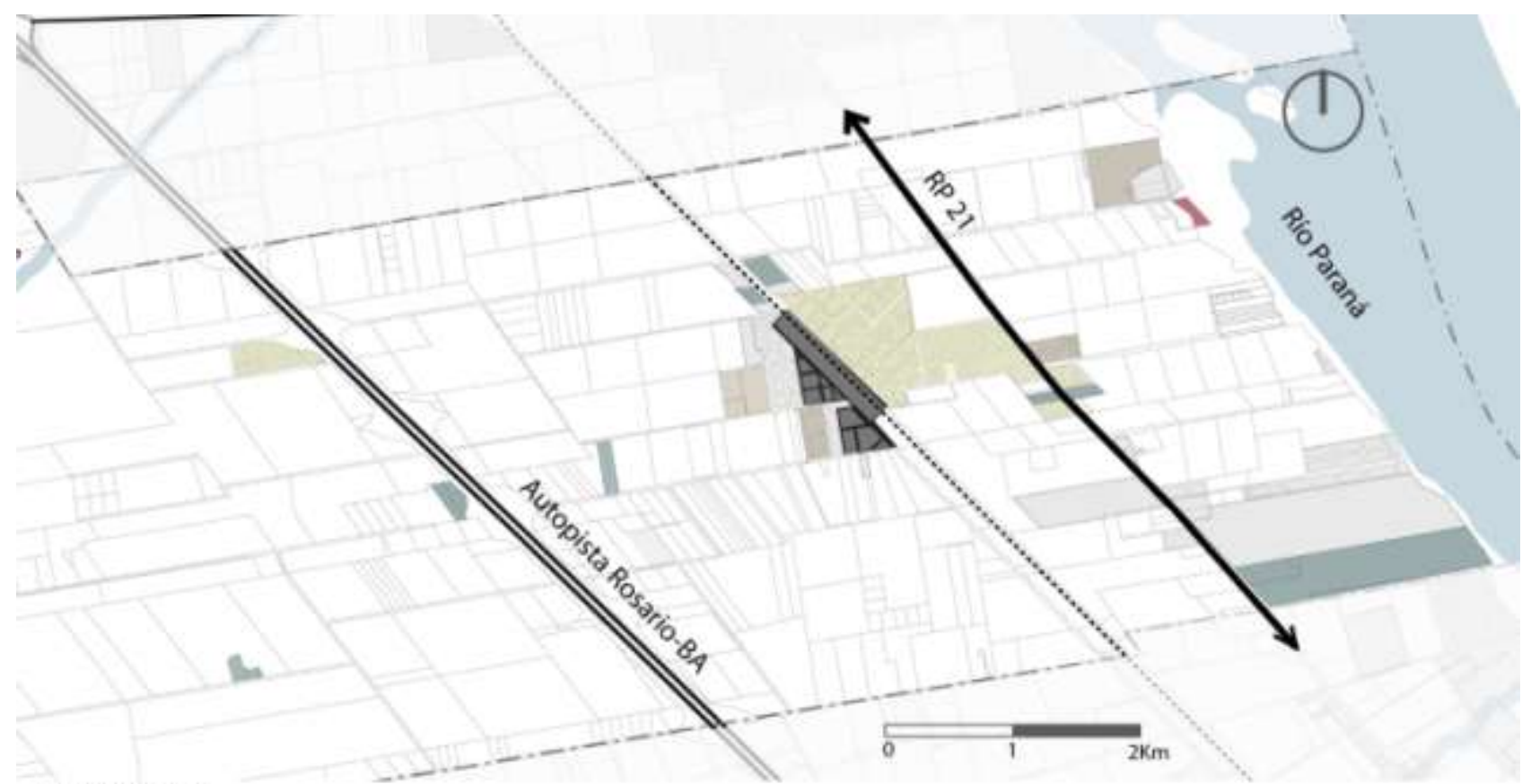

Referencias:

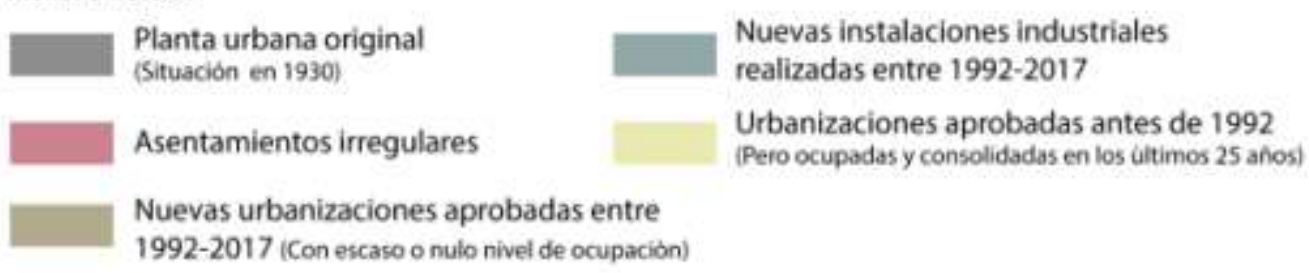

Figura 8. Transformaciones en el uso del suelo de General Lagos entre 1992 y 2017. Elaboración propia.

Esta comuna presenta una gran cantidad de suelo urbano sin edificar o con ocupación incipiente (aproximadamente registra un $23 \%$ de ocupación de ocupación de su planta urbana). Además de los loteos que se aprueban entre las décadas de1960-1980, en los últimos vente años se transforman casi 50 
hectáreas de suelo rural a urbano. Asimismo, estas nuevas urbanizaciones se localizan de manera dispersa, dado que algunas se encuentran anexas al centro histórico, pero otras sobre la ruta provincial №21, la autopista a Buenos Aires y un barrio cerrado se localiza sobre el frente fluvial del Paraná. Este último está muy desvinculado de la planta urbana (a casi $2 \mathrm{Km}$ del borde urbano más próximo) y, además, al tratarse de una urbanización cerrada que posee caletas propias ha alterado la topografía de la barranca y se encuentra junto a un asentamiento irregular de pescadores, profundizando las desigualdades socio-espaciales.

De manera que, a pesar de la baja ocupación efectiva de las tierras ya urbanizadas en General Lagos, en los últimos años se han seguido aprobando el desarrollo de nuevos loteos. Si bien se identifica una tendencia hacia la ocupación del frente fluvial, se registra gran cantidad de suelo rural que separa el centro histórico y el sector ribereño, pero que se encuentra ante la presión de especuladores inmobiliarios para ser urbanizado. A su vez, la tendencia del avance hacia el Paraná no es sólo para residencia o actividades recreativas, sino también para usos industriales y portuarios. En la ribera sur de la localidad se encuentran Louis Dreyfus Company y Basf Argentina, ocupando un sector fluvial de 130 hectáreas.

\section{- Arroyo Seco:}

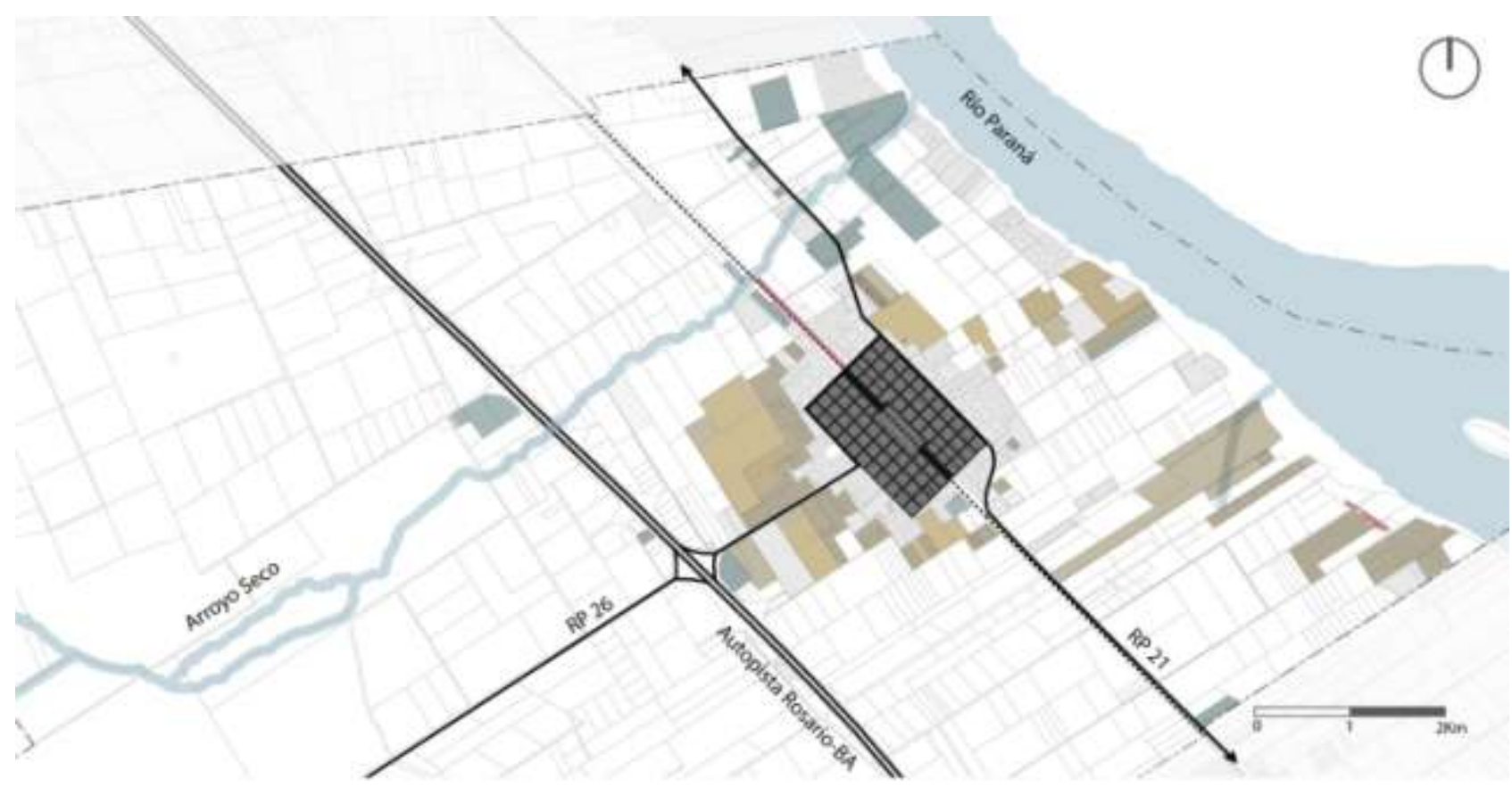

Referencias:

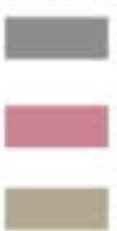

Planta urbana original
(Situación en 1930)

Asentamientos irregulares
Nuevas instalaciones industriales realizadas entre $1992-2017$

Urbanizaciones en gestión en la actualidad

Nuevas urbanizaciones aprobadas entre

1992-2017 (Con escaso o nulo nivel de ocupación)

Figura 9. Transformaciones en el uso del suelo de Arroyo Seco entre 1992 y 2017.

Elaboración propia.

En Arroyo Seco se identifica una notoria fragmentación y desconexión entre las áreas urbanizadas que fueron creciendo alrededor de la planta urbana original (organizada en torno al predio del cuadro de la Estación Arroyo Seco) y las que se extienden sobre la ribera del Paraná (por ejemplo, barrios Puerto y Acevedo) y sobre la ruta provincial $\mathrm{N}^{\circ} 26$. Del análisis de los procesos de urbanización que tuvieron lugar en los últimos años se desprende, por un lado, una clara tendencia al crecimiento de la planta urbana hacia la autopista. Las áreas habilitadas en ese sector tienden a ocuparse y entrar en proceso de consolidación muy rápidamente. Este crecimiento está preferentemente orientado a la radicación de vivienda permanente. Dicha política se complementa con la de habilitación de loteos hacia el sur del casco urbano consolidado. El problema que se visualiza es que la urbanización se va concretando por pequeños sectores sin que exista un proyecto de urbanización que los encuadre. Esto plantea el riesgo de que se pierda la oportunidad de 
proyectar integralmente un vasto sector del territorio urbano que hasta el presente se va configurando por mera adición de manzanas.

Asimismo, existe una tensión hacia el río Paraná que se pone en evidencia a partir de los proyectos de urbanización que están siendo gestionados por privados. Varios de estos proyectos se ubican sobre uno de los caminos transversales al río, por lo que, de concretarse las urbanizaciones propuestas, se estaría consolidando (por agregación de múltiples operaciones) una franja de continuidad de lo urbano hasta el río. En el sur de la jurisdicción existe un barrio cerrado en curso denominado Tierra de Sueños Boating que atraviesa la franja de suelos comprendida entre la ruta provincial №21 y el río en toda su extensión (aproximadamente 2800 metros). Estas urbanizaciones, sobre todo la última, constituyen intervenciones de gran magnitud que se instalan sobre suelos productivos de gran valor. En conjunto representan un $31 \%$ de la planta urbanizada.

\section{- Fighiera:}

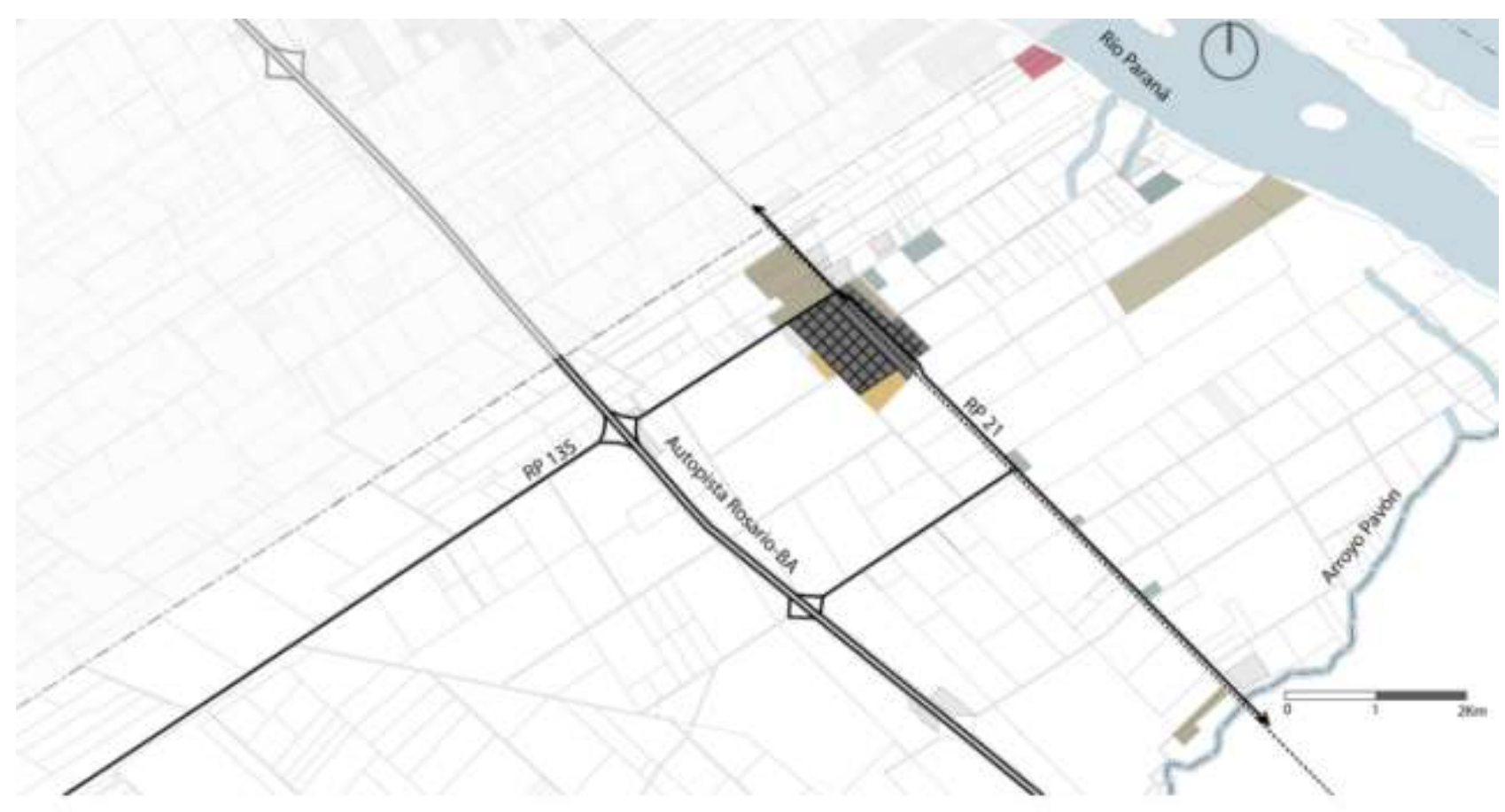

Referencias:

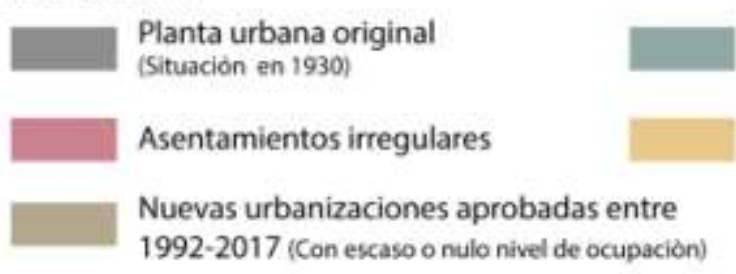

Nuevas instalaciones industriales realizadas entre 1992-2017

Urbanizaciones aprobadas antes de 1992 y consolidadas en los últimos 25 años

Figura 10. Transformaciones en el uso del suelo de Fighiera entre 1992 y 2017.

Elaboración propia.

La influencia de la demanda de suelo con excelentes características ambientales para viviendas ha llegado a Fighiera bajo la forma de grandes desarrollos inmobiliarios. El primero de ellos se ha constituido sobre el predio de la Estancia La Concepción, frente al río Paraná (un antiguo establecimiento productor de cítricos que se ha convertido parcialmente en un barrio de carácter cerrado: Azahares del Paraná). Este desarrollo (con trazado efectivizado y con ocupación incipiente) tiene una superficie equivalente al $75 \%$ de la superficie del casco urbano de la localidad.

La expansión reciente de Fighiera se refleja en una superficie urbana que se ha incrementado en el período estudiado en un $80,5 \%$. Además de los procesos vinculados al desarrollo de barrios cerrados y al crecimiento poblacional del asentamiento irregular existente en la comuna, el distrito Fighiera presenta algunas transformaciones puntuales en las áreas ribereñas: la ampliación de la arenera, la subdivisión de 
una parcela rural en quintas de fin de semana y el aumento de las instalaciones del club de pescadores sobre el Paraná; un grupo de nuevas cabañas y la ocupación incipiente de un área con urbanización aprobada previa al 2004 sobre el Pavón y un par de nuevos establecimientos industriales en el área rural intermedia entre la ruta y el río. A nivel del casco urbano, Fighiera presenta un conjunto de viviendas públicas (una manzana), procesos de consolidación de áreas con urbanización previa a 1992 y una ampliación de la planta urbana (que complementa un espacio entre el casco urbano y una urbanización preexistente) ya en proceso de consolidación.

\subsection{Desafíos y oportunidades en el planeamiento contemporáneo de la ribera metropolitana.}

Si bien la definición y aprobación de los usos del suelo es competencia de cada municipio o comuna dentro de su ámbito territorial, desde las últimas décadas del siglo XX se han propuesto y desarrollado diversas iniciativas de coordinación inter-jurisdiccional, a fin de encauzar coordinadamente la planificación de la Región Metropolitana de Rosario ${ }^{3}$. En dicho contexto, el frente fluvial del Paraná ha resultado históricamente espacio de debates, propuestas y litigios entre los diversos participantes, dado que cada localidad propone transformaciones y proyectos que muchas veces resultan incompatibles o contrapuestos con sus ciudades vecinas. Asimismo, dicha ribera está sujeta a numerosas demandas de usos diversos, pero también presenta una alta vulnerabilidad ambiental, que requiere necesariamente el acuerdo de todos los niveles estatales frente a los cambios a realizar a fin de promover su sostenibilidad socio-territorial.

En este sentido, al cambiar la perspectiva y escala analizada se indaga en el diagnóstico de la totalidad de la ribera sur metropolitana, registrándose las siguientes problemáticas:

- Se reconoce una tendencia, especialmente en las últimas dos décadas de la ocupación del frente ribereño con usos productivos y residenciales que impiden la posibilidad de la accesibilidad pública al río y de la continuidad de paseos ribereños.

- Las modificaciones aceleradas de los usos del suelo, el aumento de las terminales portuarias (junto al gran incremento del caudal de embarcaciones), la realización de amarras y caletas, entre otras acciones, contribuyen a la erosión y alteración de las barrancas, como a la modificación de las dinámicas hídricas que afectan en gran medida a todo el ecosistema fluvial.

- Existen grandes desigualdades socioambientales, dado que se registran diversos asentamientos irregulares sobre el frente fluvial (mayormente de pescadores) que presentan notables déficit de viviendas, servicios e infraestructuras (incluso algunos de ellos viviendo en sectores de riesgo de inundación), que colindan con barrios cerrados para clases sociales altas. Se destaca que muchas veces las obras realizadas para dichas urbanizaciones privadas (como las caletas y amarras), alteran las dinámicas hídricas que afectan a los habitantes que viven precariamente.

Sin embargo, a través de una planificación coordinada entre las diversas jurisdicciones municipales (o comunales) intervinientes, junto al estado provincial y a la Nación, se posibilitaría encauzar diversas oportunidades y potencialidades:

- La ribera sur de la Región Metropolitana de Rosario aún presenta importantes sectores de enclaves paisajísticos de gran valor que, a través de acciones de rehabilitación y preservación ambiental, pueden convertirse en áreas naturales de reserva con acceso público.

- La posibilidad de gestionar un sistema integrado de parques metropolitanos fluviales, a través del desarrollo de espacios públicos integrados frente al río Paraná y los arroyos Saladillo, Frías, Seco y Pavón que le confieren al corredor un potencial de uso turístico y recreativo.

- La presencia de islas cercanas a la orilla del Paraná (y correspondientes a la jurisdicción de Santa Fe) que constituyen también un gran potencial turístico-recreativo.

\footnotetext{
${ }^{3}$ En torno a las propuestas de coordinación metropolitana referidas al ordenamiento territorial del frente fluvial del Paraná, se destaca el proyecto realizado en el año 2007 por la Oficina de Asuntos Metropolitanos (OAM) de la provincia de Santa Fe, denominado "Plan de Ordenamiento de la Costa Metropolitana del Gran Rosario: Cordón Norte y Cordón Sur". Este Plan de Ordenamiento constituye un antecedente fundamental en la identificación del corredor ribereño metropolitano como un sector de transformación clave para la región del Gran Rosario. Ya que, esta franja costera, a pesar de sus diversas caracterizaciones y problemáticas, se la identifica como un paisaje unitario con gran potencial para el desarrollo regional.
} 
- La existencia de áreas intermedias entre sectores urbanos y de zonas ya urbanizadas, pero no consolidadas que posibilitan el desarrollo planificado del corredor sur, mediante acciones integradas y proyectos que incorporen programas complejos de dotación de servicios, infraestructuras, viviendas y comercios, que contribuyan a paliar el déficit existente en la RMR.

Si bien éstas son solo algunas de las problemáticas y oportunidades presentes en la ribera sur metropolitana, resultan de ejemplo para asegurar que dar respuesta a las mismas exceden las posibilidades de cada comuna. Se requiere así, la elaboración de estrategias y acuerdos integrales entre todos los niveles estatales intervinientes, encauzando los diversos intereses a través de políticas consensuadas y mecanismos de gestión que prioricen el bien común, abogando por la sostenibilidad ambiental y la mejora de la calidad de vida de todos los habitantes de la región.

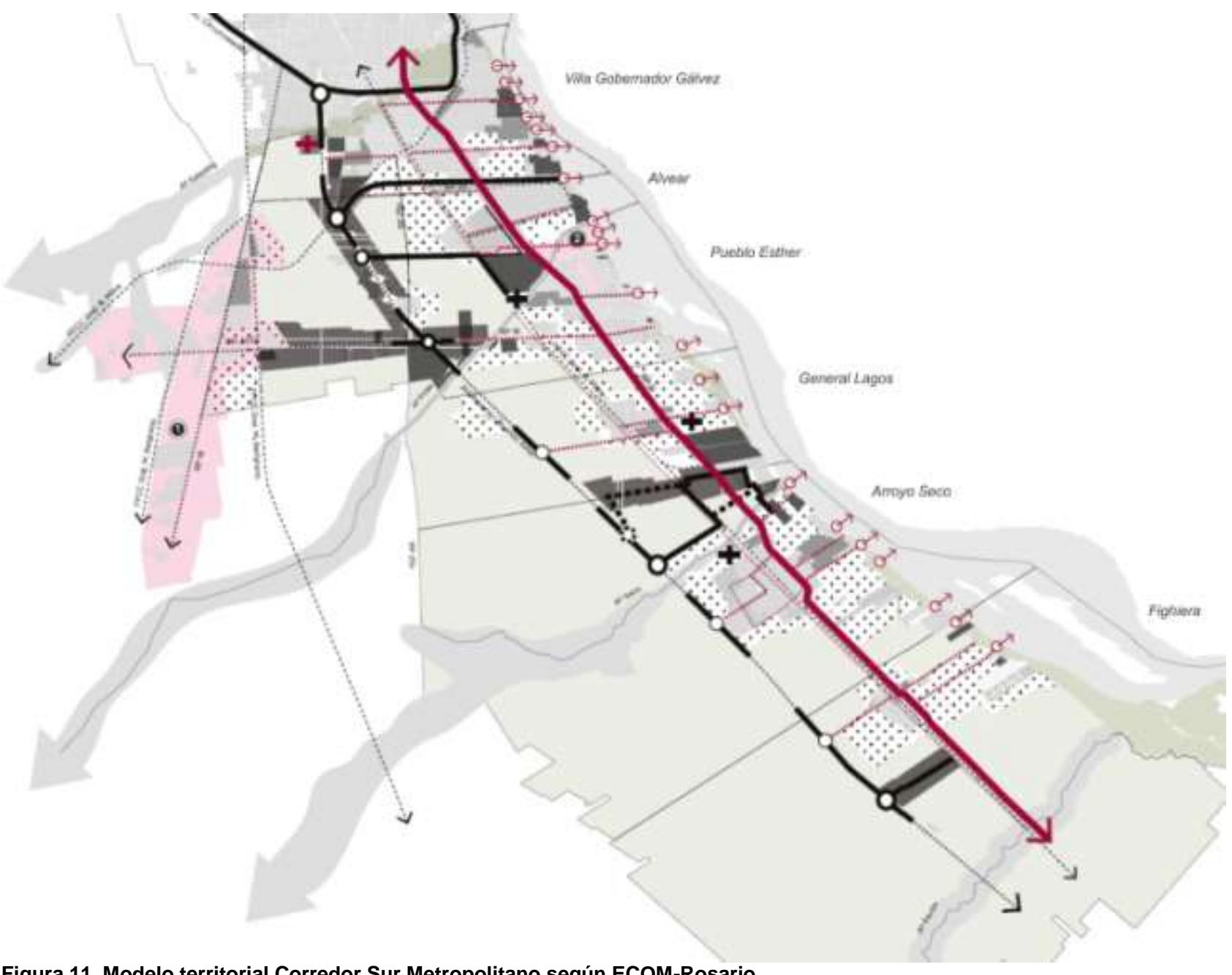

Figura 11. Modelo territorial Corredor Sur Metropolitano según ECOM-Rosario.

(Fein, 2017)

Es importante destacar que, en el marco del Ente de Coordinación Metropolitana de Rosario (creado en el año 2010), en el 2014 se acuerdan entre los distintos municipios y comunas pertenecientes al área siete directrices de ordenamiento territorial, a fin de ordenar y priorizar la gestión de los procesos de transformación metropolitana. Siguiendo estas directrices, durante los años 2016 y 2017 se lleva a cabo el desarrollo de los Planes Urbanos Locales de 13 localidades. Es así, que se confeccionan los planes urbanos de las seis localidades aquí estudiadas correspondientes al corredor sur metropolitano, respondiendo a las necesidades y objetivos de cada poblado, pero respetando el modelo territorial deseado del corredor sur metropolitano.

Si bien este proceso es muy reciente y se presentan diversas vicisitudes en el proceso que ocasionan cambios y modificaciones del desarrollo de las propuestas, se destaca que, a través de éste, existe un creciente reconocimiento de la perspectiva metropolitana y la necesidad de ampliar la mirada en los 
procesos urbanos territoriales como en el debate, consenso y acuerdo entre las diversas demandas y actores intervinientes.

\section{REFLEXIONES FINALES}

A través del análisis crítico de las transformaciones que tienen lugar en la ribera sur identificamos que en las últimas décadas se produce un proceso acelerado de cambios de uso de suelo, generalmente de actividades rurales a usos residenciales y productivo-industrial. Asimismo, se registra que dichas transformaciones no se anticipan a través de una planificación previa, de lo contrario, cada municipio y/o comuna autoriza gradualmente nuevas urbanizaciones a partir de cada solicitud particular, estando fuertemente condicionado por la presión de cada promotor inmobiliario. Por lo cual, en el período estudiado, no solo se denota la carencia en el acuerdo y coordinación interjurisdiccional de las transformaciones de la región, sino que también existe una notoria falencia en cada ámbito local de realizar estrategias de planeamiento urbano-territorial de manera anticipada y consensuada con todos los actores involucrados de la transformación de cada ciudad.

Si bien desde la década del 2010, a través de la conformación del Ente de Coordinación Metropolitana de Rosario, el acuerdo de las directrices metropolitanas en el 2014 y el desarrollo de cada uno de los planes urbanos de las localidades correspondientes al corredor sur (entre 2016 y 2017), constituye un notable avance de la coordinación metropolitana y la articulación multiescalar y multiactoral en el planeamiento territorial, todavía este proceso es reciente y requiere profundizar mecanismos de continuidad y mayores estrategias de consenso, participación y acuerdos que perduren más allá de los gobiernos políticos de turno en cada jurisdicción.

Los frentes fluviales resultan espacios complejos que requieren la articulación profunda entre todos los niveles existentes en las dinámicas urbanas, fluviales y territoriales. Están sujetos a numerosas demandas que necesitan indudablemente la presencia activa y anticipada del Estado en todos sus niveles, trabajando de manera coordinada, como promotor clave del modelo territorial anhelado. Las aspiraciones de las comunidades locales, sus reclamos y expectativas sobre estos espacios, resultan centrales en el proceso de transformación que se lleve a cabo. Como también así, resulta esencial la participación de la sociedad en las distintas etapas de cada proceso: desde su planificación, la definición de las estrategias de intervención, la ejecución de los proyectos acordados y su continuidad en el tiempo.

\section{BIBLIOGRAFÍA}

ANSALDI, M.D.; COREA, M. y PLA, L. (1972). Prefectura del Gran Rosario - Cuaderno N ${ }^{\circ} 14$ de Prefectura del Gran Rosario. Rosario: Publicado por la sección de prensa y difusión Depto. Promoción y Desarrollo.

BREEN, A. \& RIGBY, D. (1994). Waterfronts. Cities reclaim their edge. Estados Unidos: Kim Hupp Lee.

BRUTTOMESSO, R. (1993). Waterfronts. A new Frontier for Cities on Water. Venecia.

(2004) Complejidad en la relación puerto-ciudad. Revista It, №67, 22-31.

CABALLERO, A. (Coord) (1991). Proceso de Formación urbano-territorial y dinámica de transformación del Área Metropolitana de Rosario. Rosario: CFI.

CALZADA, J. y DI YENNO, F. (2017). Gran Rosario es el nodo portuario exportador sojero más importante del mundo. Informativo Semanal Bolsa de Comercio de Rosario, Año XXXV, № Edición 183.

FEIN, M. (Ed.) (2014). El Área Metropolitana de Rosario: directrices para la concertación de un modelo territorial. Cuaderno 3. Rosario: ECOM.

FEIN, M. (Ed.) (2017). Colección Planes Urbanos Locales del corredor sur de Rosario: Villa Gobernador Gálvez, Alvear, Pueblo Esther, General Lagos, Arroyo Seco y Fighiera. Rosario: ECOM.

FONT, A. (Ed.) (2007). La explosión de la ciudad. Transformaciones territoriales en las regiones urbanas de la Europa Meridional. España: Ministerio de Vivienda. 
GALIMBERTI, C. (2015). La reinvención del río. Procesos de transformación en la ribera de la Región Metropolitana de Rosario, Argentina. Rosario: UNR Editora, Colección Tesis Doctorales A\&P.

GALIMBERTI, C. (2014). Reflexiones en torno a las transformaciones de waterfronts contemporáneas. Revista Arquitectura y Urbanismo, vol. XXXV, n². 19-35

HOYLE, B. (2000). Global and Local Change on the Port-City Waterfront. Geographical Review (New York), $N^{\circ} 3,395-417$.

JANOSCHKA, M. (2002). El nuevo modelo de la ciudad latinoamericana: fragmentación y privatización. EURE (Santiago), 28 (85), 11-20.

NEUMAN, M. (2006). La gobernanza regional metropolitana. Grandes redes institucionales y fenómenos de multiescala. Urban (Madrid) №11 (2), 6-23. 